\title{
Silifke Uzuncaburç'ta Geleneksel Yöntemlerle Pekmez Yapımı Üzerine Halk Bilimsel Bir İnceleme
}

\author{
Dr. Öğr. Üyesi Turgay Kabak \\ Bayburt Üniversitesi, İnsan ve Toplum Bilimleri Fakültesi \\ Türk Dili ve Edebiyatı Bölümü \\ turgaykabak@gmail.com
}

Öz

Mersin ili Silifke ilçesine bağlı olan Uzuncaburç, tarihi milattan önceki dönemlere kadar giden eski bir yerleşim yeridir. Türklerin Anadolu'ya yerleşmeye başladığı dönemlerde konar-göçer Yörük Türkmenlerin yerleştiği Uzuncaburç'ta en temel geçim kaynakları tarım ve hayvancılık olmuştur. Hayvan olarak keçi, koyun gibi küçükbaş hayvanlar besleyen yöre halkı, tarımsal ürün olarak da buğday, arpa, nohut gibi tahılları yetiştirmişlerdir. Ancak bölge halkının yetiştirdiği tek tarım ürünü bunlar değildir. Bunların dışında bir de bağcılık vardır. Özellikle yerleşim yerinin merkezinde ve merkez çevresinde büyük miktarda üzüm bağı bulunmaktadır. Bu bağlamda yörede bağı olmayan aile neredeyse yoktur. Bağcılığın bu kadar yaygın olmasının en büyük sebebi Uzuncaburç'ta kökeni Türklerden önceki dönemlere kadar uzanan köklü bir bağcılık kültürü olmasıdır. Bu makalenin amacı yöredeki geleneksel pekmez üretim yöntemlerinin tespit edilip bu üretimin kültürel boyutunu araştırmaktır. Çalışmada saha araştırma yöntemi ile pekmez üretimi, bu üretim esnasında kullanılan etnografik araç gereçler ve üretim sırasında ortaya çıkan sözlü kültür ürünleri tespit edilip gelenek açısından incelenmiştir. Çalışmanın sonucunda Uzuncaburç halkının kendisinden önceki bölge sakinlerinden devraldıkları bağcıllk geleneğini devam ettirdikleri, onların kullandığı şarap üretim yöntemlerini daha da geliştirerek pekmez üretiminde kullandıkları ve Orta Asya Türk mutfağından getirdikleri pekmez üretim geleneğini yeni coğrafyanın şartlarına uyarlayarak başarılı bir şekilde devam ettirdikleri tespit edilmiştir.

Anahtar Kelimeler: Silifke, Uzuncaburç, pekmez yapımı, yerel mutfak, mutfak kültürü.

\section{A Folklore Study on Traditional Grape Molasses Production in Silifke Uzuncaburç}

\footnotetext{
Abstract

Uzuncaburç, which is connected to the Silifke district of Mersin, is an old settlement that goes back to the previous periods of BCE. At the time when the Turks started to settle in Anatolia, the main sources of livelihood were agriculture and animal husbandry in Uzuncaburç, where nomadic Turkmen settled. Local people who feed animals such as goat and sheep have grown wheat, barley and chickpeas as agricultural products. However, these 
are not the only agricultural products grown by the people of the region. There is also a viticulture outside. There is a large amount of vineyards, especially in the center and around the settlement. In this context, there is almost no family in the region. The main reason why viticulture is so widespread is that Uzuncaburç has a deep-rooted culture of viticulture, whose origins go back to the previous periods of the Turks. The aim of this article is to determine the traditional molasses production methods in the region and to investigate the cultural dimension of this production. In this study, molasses production and ethnographic tools used during this production and oral culture products that were produced were determined and examined in terms of tradition by field research method. As a result of this study, it was determined that the people of Uzuncaburç continued the tradition of viticulture they took over from the previous inhabitants of the region.

Keywords: Silifke, Uzuncaburç, grape molasses production, local cuisine, kitchen culture. 


\section{GíRIŞ}

Kuruluşu M.Ö. 3000'lere uzanan ve bugünkü adını Makedonyalı kumandan ve daha sonra Suriye komutanı olan Selefkos Nikador'dan alan Silifke ilçesinin (Aslan, 1988, s. 37) merkezine $30 \mathrm{~km}$ mesafede, Torosların eteklerinde $1200 \mathrm{~m}$. rakımda kurulmuş olan Uzuncaburç, bölgenin en önemli yerleşim yerlerinden birisidir.

İlk yerleşimi Helenistik döneme kadar uzanan ve günümüzde Antik Yunan ve Roma döneminin izlerini barındırdığı tarihi eserlerle canlı bir şekilde koruyan Uzuncaburç'un tarihte bilinen ilk ismi Diocaiseria'dır. 6 katlı Helenistik kule, Zeus mabedi, Helenistik kule mezar gibi antik dönem eserleriyle önemli bir yerleşim yeri olan kente, Roma döneminde de bu önemini korumuş Tyche mabedi, tiyatro, portico, zafer kapısı ve suyolları gibi sanat değeri yüksek eserler ilave edilmiştir. Diocaiseria, Helenistik dönemde Olba adı ile anılan bölgenin dinî merkezi olması nedeniyle bugünkü Uzuncaburç'un kurulduğu alan önemli bir merkezdi. Ancak bu alanın önemi sadece dini merkez olmasından gelmiyordu. Aynı zamanda bu bölge önemli bir şarap üretim merkeziydi. Roma döneminde devrin şartlarına göre Uzuncaburç'ta yetiştirilen üzümlerden elde edilen şaraplar Uzuncaburç ile Kızkalesi arasında taş döşenerek yapılan ve bugün adına "Roma Yolu" denilen 30 km'lik döşeme yoldan kervanlar vasitasıyla Akdeniz sahillerine indirilmekte, buradan da gemilerle Atina, Mısır gibi uzak yerlere taşınmaktadır. (Başal, 1993, s. 36; Boysal, 1963; Taşkıran, 2009). Bölgeyi Akdeniz ile bağlayan bu ticaret yolunun da katkısı ile üzümcülük Uzuncaburç'ta önemli bir geçim kaynağı olmuş görünüyor. Bunun en büyük delili bugün yerleşim yerinin her yerinde görülen ve halk arasında "şarap yalağı" (Görsel: 7) olarak adlandırılan şarap üretim yerleri ile yakın zamanlara kadar halk arasında "cavurdan kalma bağ" diye adlandırılan eski bağlıkların bulunmasıdır.

Anadolu'yu daha Miladın ilk yıllarında bir yurt olarak benimseyip yerleşmeye başlayan Türklerin mesken tuttuğu bölgelerden birisi de Toroslar olmuştur. Bu dönemde Avşarların önemli kollarından birisi olan Recepli oymağı tarafından iskân edildiği (Şükürov, 2007, s. 149-200) için adı Recepli köyü olan yerleşim yerinin daha sonra ismi değişmiş ve merkezde bulunan Helenistik burçtan dolayı Uzuncaburç ismi verilmiştir. Bölgeye yerleşen konar-göçer Avşar Yörükleri temel iktisadi uğraş olarak hayvancılıkla uğraştıkları halde, daha önceki sakinlerden kalan üzüm bağlarını da ihmal etmemişler. Bağcıllğı geliştirerek hem iktisadi hem de kültürel bir uğraş haline getirmişlerdir.

Bugün Uzuncaburç'ta yöresel isimleriyle namrun, tilki kuyruğu, ak üzüm, gök üzüm, Mudanya karası, kalecik karası, alfoz, kardinal, Şakir üzümü, sebil gibi birçok üzüm çeşidi yetiştirilmektedir. Özellikle Ankara, Adana, Konya gibi illerden gelen tüccarların aldığı bu üzümler yöre halkının en önemli gelir kaynaklarından birisidir. Üzümlerin bağlardan toplandığı "Ağustos - Ekim" ayları yöre insanı için tam anlamıla bir bağ bozumu dönemidir. Bu dönemde ilk önce yaş satılacak olan üzümler kesilip satılır. Daha sonra kurutmalık üzümler kesilir ve üzüm kurutma işlemi yapılır. Kurutulan üzümlerin bir kısmı satılırken bir kısmı da kışlık olarak saklanır. En son da pekmez yapılacak olan üzümler kesilir. Bu dönem yöre halkının geçmişte imece usulüyle, günümüzde ise yevmiyeci tutma yoluyla üzümleri hasat ettiği bir dönemdir. Bu sebeple bazı insanlar (özellikle de kadınlar) bu dönemde yevmiye ile üzüm keserek ev ekonomilerine katkıda bulunmaktadır (KK: 1)

Uzuncaburç'un bağcllığa elverişli bir iklimi vardır. Kışları karlı ve soğuk, yazları da sıcak ve güneşli geçtiği için üretilen üzümler son derece kalitelidir. Kışın kar yağması bağların köklerinin iyice suyunu almasını sağlar. Yazların sıcak ve kurak geçmesi de 
üzümün iyice "şıralanmasını" sağlar. Bu sebeple hem üzümler hem de üzümlerden yapılan pekmez son derece kalitelidir (KK: 1, 2)

\section{BULGULAR}

Bağdan toplanan üzümlerin pekmez yapımı için getirildiği yere halk arasında "pekmezlik, şıhranalık" denir. Şıhranalık aslında üzümlerin çiğnenerek posa ile suyunun birbirinden ayrıldığı havuzdur. Daha sonra suyun pişirildiği yere ise "fırın" denir (KK: 1,2).

15 Eylül- 15 Ekim arasında bağdan toplanan pekmezlik üzümler sandıklarla şıhranalığa getirilir. Daha sandıkta iken hortumla iyice yıkanarak üzümler tozundan, pisinden arındırılır. Burada zaman varsa bir iki gün sandıkta durdurulur ki böylece üzümler yumuşamış olur. Yumuşayan üzümler şıhranalığa dökülür ve temiz bir çizme ile çiğnenmeye başlanır. Bu sırada üzümler çiğnendikçe şıhranalığın borusunun önünün tıkanmasıyla suyun birikmesi sağlanır. Daha sonra borunun önü açılarak konulan bakır kazana üzüm suyu akar. Üzüm çiğnenirken hem daha kolay ezilmesi hem de pekmezin renginin berrak olması için sık sık üzerine ak toprak (beyaz kireçli toprak) serpilir. Bu şekilde bir süre çiğnenen üzüm posası delikli çuvallara katılarak sıkıştırılmak suretiyle ikinci defa çiğnenir. Bu çiğneme esnasında da üzerine ak toprak serpilir. Bir miktar su da çuvalın üzerine dökülür ki üzümü yumuşatıp suyunun çıkmasını kolaylaştırsın (KK: 1,3,4).

Bu şekilde bütün üzümler çiğnenip suyu ile posası birbirinden ayrıldıktan sonra kazana alınan üzüm suyu bir süre (1 saat gibi) kaynatılır. Bu işleme "haşlama" denir. Su tavaya alındığı zaman yüzü çizik çizik olmuşsa haşlama işlemi tamamlanmış demektir. Haşlanan su 1 gün süreyle durulması için dinlenmeye bırakılır. Ertesi gün dinlenen su, kumaştan, seyrek bir tülbent sayesinde süzülerek, altı önceden yakılmış olan pekmez tavasına alınır. Böylece suyun içerisindeki topraktan ve diğer yabancı maddelerden arındırılmış olur. Pekmez tavası, bakırdan yapılan altı yuvarlak şekle sahip bir çeşit kazandır. Bu kazan fırına oturtulur. Pekmez fırını etrafı, 1sı yalıtımı için ak toprakla sıvanmış, sadece ağız kısmı açık olan arkadan da duman çıkması için bir bacası bulunan bir çeşit ocaktır. Bu ocağın içine oturtulan pekmez tavasının etrafı hem ısı kaybı olmaması hem de duman çımaması için hamur ile iyice sıvanır. Tavanın içi pekmezle doldurulduktan sonra altı daha kuvvetli bir şekilde yakılır ve pekmez kaynamaya başlar. Pekmez kaynarken bir taraftan sohbet edilirken bir taraftan da "kevgir" denilen delikli, uzun saplı aletle savrulur. Bu şekilde kaynayan suyun tavada yanması engellenir. Çünkü su kaynadıkça buharlaşır ve geriye suyun şırası yani pekmez kalır. Su şıralandıkça ${ }^{1}$ koyulaşır ve yanma tehlikesi oluşur. Bu yanma tehlikesini bertaraf etmek için kaynayan su sürekli olarak kevgir ile savrulur (KK: 5).

Pekmez belli bir koyuluğa ulaştığı zaman pekmez tavasından boşaltmak gerekir. Pekmezin indirme kıvamına geldiğini anlamanın iki yolu vardır. Bunlardan birincisi şudur (KK: 4,5):

Pekmezden bir miktar alınıp toprağa damlatılır. Eğer damlatılan pekmez toprak üzerinde toparlanıp yuvarlak oluşturuyorsa pekmez olmuş demektir. Aksi takdirde toprakta dağılıyorsa henüz olmamış demektir ve kaynatmaya devam edilir.

İkinci yöntem de şudur: Tavadan sıcak pekmez bir tabağa alınır. Daha sonra bu tabak içerisine soğuk su doldurulmuş daha büyük bir tabağın içine konulur. Eğer pekmez bu

${ }^{1}$ Tatlanmak anlamında yöresel bir kelimedir. Ayrıntılı bilgi için bkz. TDK Türkiye Türkçesi Ağızları Sözlüğü. 
şekilde soğutulduğunda aşırı akışkan ise (yöre ağzıyla cıvık) henüz olmamış demektir, kaynatmaya devam edilir. Aksine koyuluk derecesi iyiyse pekmez olmuş demektir ve kaynayan pekmez, pekmez tavasından bir bakır helke (bakraç) yardımı ile boş kazanlara alınarak soğumaya bırakılır. Daha sonra soğuyan pekmezler toprak testilere doldurularak kışın çıkarılacağı zamana kadar genelde güneş görmeyen ahırlarda bekletilir. Pekmezin kaynatarak aşırı koyulaşmış haline "akıda" denir. Akıda az miktarda yapılır (KK: 2).

Pekmez kaynatılırken sadece oturup pekmez tavasının başında beklenmez. Hoş vakit geçirmek için pekmez fırınından alınan kömürlerle köz çayı demlenir. Ayrıca yine fırından alınan közlerle çörek yapılır ve bu çörekler çayla birlikte yenilir. Ayrıca pekmez kaynatmak uzun sürdüğü için bu esnada bol bol fikra, masal, hayalet hikâyesi [Memorat] de anlatılır (KK: 2,4,5).

$\mathrm{Bu}$ anlatmalardan tespit edilebilenler şunlardır:

\subsection{F1kralar}

\section{Rüyamda Gördüm}

Eskiden yaşlı kocanın birisi her gün altına pisliyor, karısı da kızıyormuş. Bir gün yine sabah bir kalkmış ki ortalık berbat, büyük abdestini kaçırmış, karısı duysa öldürür. Karısını uyandırmış, demiş ki:

"Karı bu gün rüyamda ne gördüm biliyor musun? Minare minare üstüne, onun üstüne tepsi, onun üstüne seni, üstüne de beni koydular" demiş. Karısı da

"Korkmadın mı koca" demiş. Koca:

"Korkmaz mıyım karı altıma bile ettim" demiş (KK: 1).

\section{Bezdirme}

Köyde eskiden Deliâbak derler bir koca yaşarmış, kocanın eli birazcık sıkıymış. Bir gün eve misafirler gelmiş. Deliâbak koca misafirlere bezdirme ikram etmiş, misafir de bezdirmeyi çok severmiş, yedikçe yemiş yedikçe yemiş, kocanın içi gitmiş ama bir şey diyememiş. Yemekten sonra oturmuşlar sohbet etmişler falan vakit geç olmuş misafirler kalkmış, Deliâbak da onları yolcu etmiş, tabi o zamanlar şimdiki gibi lamba falan yok çıranın şavkında gidiyorlar. Misafir çadırdan birazcık uzaklaştıktan sonra başlamış bağırmaya. , Deliâbak da zannetmiş ki adamın yediği bezdirmeler midesine oturdu ondan bağırıyor.

"Yer miydin bezdirmeleri" demiş.

Hâlbuki karanlıkta adamın kızını kaçırmışlar ondan bağırırmış (KK: 3, 8).

Nasradan'in Hikâyesi

Nasradan'ın keçileri savruk olmuş, hoca başlamış teke aramaya, bütün komşularından istemiş vermemişler. En sonunda hocanın canı sıkılmış:

"İki geçiyi gendim de yünürürüm, ha deke dölü olsun dediyidim" demiş (KK: 5).

Helva

Eskiden tezgâhta çalışırken öğle yemeğinde herkese helva da dağıtılırmış. Insanlar sıraya girer helvalarmı, ekmeklerini, yemeklerini alır giderlermiş. Sıra Mehmet Okur'a gelmiş. Aşçı: 
"Kaç kişilik" diye sormuş. Mehmet Okur da:

"Mehmet Okur, Ulak Mehmet, bir de ben" deyip üç kişilik helvayı almış. Aş̧̧ı az sonra bir düşünmüş ki bunun saydığı üç adam da aynı kişi (KK: 2).

\section{Mercimek Çorbası}

Eskiden yaşlı bir karı koca varmış bunların kışın ortasında odunları bitmiş. Koca baltayı almıs,

"Ben öğlene gelirim" diyerek oduna gitmiş. Öğlen olmuş koca gelmemiş. Karı da

"Herhalde koca odunu bitiremedi, karnı da acıkmıştır, yemeğini dağa götüreyim bari" demiş. Bir mercimek çorbası yapıp doğru odun dă̆ına gitmiş, uzaktan bakmış ki koca bir ă̆acın dibinde oturmuş, dişleri görünüyor. Karı kendince kocaya:

“ Gülersin gülersin

Mercimek çorbasını dilersin" demiş. Kocanın yanına varınca görmüş ki koca gülmüyormuş, soğuktan donmuş ölmüş ondan sırtarırmış (KK: 7).

\section{Sırçanlı (Fareli) Pekmez}

Eskiden adamın biri, bir yere arkadaşını ziyarete gidiyormuş, yolda karnı acıkmış, bir çadıra sapmış. Çadırda sadece bir kadınla çocuk varmış. Kadına: "Sen kimin karısısın?" Falan diye sormuş, ondan sonra, "Karnım aç bana bir şeyler getir de yiyeyim" demiş. Çocuk da bir sahana (bakır tabak) pekmez katmış, yanına ekmek koymuş getirmiş. Adam bir sahanı yemiş doymamış, çocuktan bir sahan daha istemiş. Çocuğa "Pekmezi çok yedim anan kızmasın" demiş. Çocuk da: "Kızmaz kızmaz zaten sırçan düştü de dökecektik" demiş. Adamın midesi bulanmış hemen sahanı çadırdan dışarı fırlatmış. Çocuk: "Ana, misafir bizim köpeğin yal çană̆ını saldı" demiş (K: 6).

\section{Zengin Yiyeceği}

Eskiden Uzuncaburç'ta herkes davarcı olduğu için köyde durup da bă̆ bahçe işlerine bakan olmazmış onun için de pekmez çok kıymetliymiş.

Adamın ikisi sohbet ediyorlarmış. Biri ötekine:

"Padişah ne yiyordur acaba?" demiş. O da:

“Ne yiyecek zengin p.... pekmez yiyordur" demiş (KK: 7).

\subsection{Efsaneler}

\section{Bireyni Cavuru}

Eskiden buralarda Bireyni cavurları yaşarmış. Karamanoğullar buraları fethetmeye başlayınca Bireyni'ler Kızılgeçit'e kadar çekilip oradaki bir mă̆araya sı̆̆ıımışlar.

Gözcü bir bakmış ki uzaktan toz duman içinde atlılar geliyor: " Karamanoğulları geliyor" diye bağırmış o sırada leğene un eleyen kadın korkusundan unu dışarı elemiş ve o, dışarı elediği un orada taşa dönüşmüş (KK: 6, 9).

\section{Bireyni Kalesi}

Çok eski zamanlarda Kızılgeçit’te Bireyni cavurları varmış. Bunların bir kalesi varmış ve orada yaşarlarmış. Aynı dönemde orada bir de Şıh Zekeriya derler bir mübarek yaşarmış. Cavurlar ondan çok korkarlarmış. Bir gün şıhı bir mă̆arada kıstırmışlar, mă̆aranın içine ateş atarak "Burada yakalım da bundan kurtulalım" demişler, Şıh Zekeriya elindeki 
asasını mağaranın topră̆ına vurmuş ve yerden fışkıran su ile ateş sönmüş. Bunu gören cavurlar Şıh ile başa çıkamayacaklarını anlayıp "Biz sana bir değirmen ile bir tekke verelim sen burada otur, biz de sana karışmayalım" demişler.

O zamanlar Karamanoğlu Mehmet Bey'in soyundan gelme Yedi Kardeşler varmış ve bunlar Karaman'dan çııı Silifke'ye kadar her yeri fethetmişler. Silifke'ye gelince Kızılgeçit'te yaşayan Bireyni cavurlarının Türk ve Müslüman halkı rahatsız ettiklerini duymuşlar. Yol boyundaki yerleri fethederek Kızılgeçit'teki Bireyni Kalesinin önündeki Şıh Zekeriya'nın değirmenine gelmişler.

"İhtiyar burada Bireyni cavurları yaşarmış ve halka huzursuzluk verirlermiş. Bunların kalesini nasıl alcă̆ız sen bize yol göster" demişler.

Şıh Zekeriya "Yedi at torbası tahta çivi düzüp kalenin kıble tarafina bunları en büyüğ̈̈nüz en önde olacak şekilde çaka çaka çıkacaksınız, çıkarken bir zımbıltı gürültü duyacaksını ama kesinlikle arkanıza bakmayacaksınız, bakarsanız düşersiniz. Bu şekilde kaleye çıarsanı kaleyi feth edersiniz" demiş.

Yedi kardeş yedi at torbası tahta çivi düzüp kalenin kıble tarafindan çivileri duvara çakarak çıkmaya başlamışlar. En küçük kardeşin içinde bir şüphe oluşmuş "Nasıl oluyor da tahta çivi taş duvara geçiyor?" diye aklından geçirmiş. Tam duvarın yarısına çıkmışlar ki bir gümbürtüdür kopmuş, küçük kardeş merak edip arkasına bakmış, bakmasıyla düşmesi bir olmuş.

Tam o sırada kralın kızına âşık olan çoban da oradan geçiyormuş kavalıyla kral kızına seslenmiş:

“ Kayacular kaya keser

Korumundan yeller eser

Kara köpek kanlar kusar

Vardı kral kızı Karamanoğlu" der. Kralın kızı baba bak dinle çoban neler söylüyor deyince, kral kızına: "Senin çobanda gözün var yıkıl karşımdan demiş. O anda altı kişi kalan kardeşler kaleyi ele geçirmişler.

Kaleden, katırlarıyla ancak katır sığabilecek kadar genişlikte bir mă̆arayı izleyerek demir kapıdan kaçan kırk cavur, Karaman'ın Kızıllı Köyü'ne yerleşmiş (KK: 6).

\subsection{Memoratlar}

\section{Püf Koca}

Ĕ̆ri Kuyu mevkine giderken ki yol kavşă̆ında bazı geceler insanlar oradan geçerken bir köşeye çömelmiş yaşlı bir koca püfff dermiş. Insanlar bakınca anında kaybolurmuş. Bazen de oradan zinciri yerde sürünen bir at dörtnala koşuyormuş gibi ses gelirmiş, ama at hiç görünmezmiş $(\mathrm{KK}: 3,10)$.

\section{Asslan Gelin}

Bir kız ile oğlan birbirlerini çok sevmişler. Ailelerinin karşı çıkmasına rağmen kaçarak evlenmişler. Illk başlarda çok iyi anlaşıyorlarmış, birbirlerine asla kötü söz söylemiyor, birbirlerinin kalbini kıracak bir şey yapmıyorlarmış, her şey çok güzelmiş. Bir gün oğlanın annesi bir muska yaptırmış ve bir kadına bu muskayı vermiş. Kadın gelinin yanına misafir olarak gitmiş. Vardığında gelin çamaşır yıkıyormuş, sohbet etmişler falan derken kadın muskayı gelinden gizli çadırlarının kapısına gömmüş. Kadın gittikten sonra 
evde işler değişmeye başlamış, gelinle kocası her gün dövüşmeye başlamışlar. Bu kavgaların birinde kocası gelini döve döve öldürmüss sonra kardeşiyle birlikte götürüp bir ă̆aca asmışlar ve gelin kendini astı diye bütün köylüye haber vermişler. Daha sonra gelin her yıl asıldığı gün asıldığı yerde öyle bir bağırıyormuş ki bütün o dağlar zingirdiyormuş. Kocası o günler köye gidiyor oradaki evde kalmıyormuş. Bir gün köye gidememiş, mecburen evde kalmış. Gece uyurken mutfaktan bir tıngırtı gelmiş, adam:

"Herhalde mutfă̆a kedi girdi, şunu bir kovayım" demiş. Tam doğrulacă̆ı sırada üzerine kocaman bir karaltı çökmüş boğazını sıkmış, tam ölecekken adam son nefesinde besmele çekmiş, o anda kara bulut kaybolmuş, adam da kalktığıyla soluğu köyde almış. Bir daha da o evde kalmamış (KK: 1$)$.

\section{Cümbüş}

Uzuncaburç'tan Ŭgra'ya giderken yol üstünde bir cavur mezarliğı var, o mezarlığın da tam karşısında bir harman. Bir gün adamın birisi Uzuncaburç'tan Uğra'ya giderken tam oraya gelmiş. Harmanda bir cümbüş, düğün oluyormuş, herkes oynuyor, davullar çahyor, yemekler yeniyormuş. Oradakiler hemen adamı da sofraya buyur etmişler. Adam sofraya oturmuş, eline ekmeği de almış tam ă̆zına katacakken Besmele çekmiş o anda orada bir toz duman bulutu oluşmuş, ne düğ̈̈n kalmış ne dernek, adamın elindeki ekmek eşek tezeğine dönüşmüş. Hâlbuki orda Cinler cümbüş yapıyormuş, eğer Besmele çekmese adama eşek tezeğini ekmek diye yedireceklermiş (KK: 7).

\section{Yanan Karı}

Eskiden yaşlı bir karıyı, çocukları akşam evde yalnız bırakıp gezmeye gitmişler. Çocuklar gittikten sonra ocaktan çıkan çıngıyla evde yangın çıkmış ve karı yanarak ölmüş. Ondan sonra bazı geceler oradan geçen insanların önünden bir ateş parçası hızla geçiyormuş. Bazen de yaşlı bir karı adamın önünden hızla geçip yok oluyormuş. Bir keresinde otobüsle düğ̈̈nden gelen insanlarm önüne tam oradan geçerken bir karı çıkmış. Şoför hemen frene basmış, herhalde karıyı çarptık demişler, inip bakmışlar dışarıda ne karı var ne bir şey, o anda yok olmuş (KK: 6, 9, 10).

\section{Define}

Köyde birkaç adam define bulup zengin olmuşlar. Bir gün adı Süleyman olan birisi kahvede arkadaşlarıla sohbet ederken "SSunlarn definelerini çalsam bir" falan demiş. Bundan kısa süre sonra da adamların paraları çalınmış, adamlar Süleyman'ın öyle dediğini öğrendikten sonra onu takip etmeye başlamışlar. Bir gün gece geç vakit kahveden çadır evine giderken yolda, ıssız bir yerde önünü kesmişler ve boğarak Süleyman'ı öldürmüşler. Ondan sonra her yıl, Süleyman'ın öldürüldüğ̈̈ tarihte öldürüldü̆ğ̈ yerde ateş yanıyormuş. Bir gece Süleyman'ın öldürülddüğ̈̈ yerin tam karşısındaki tepede oturan bir köylü gece tuvalete kalkmış. Tuvalete giderken bir bakmış ki Süleyman'ın yıkandı̆̆ı yer (Teneşirlik)'den gömüldü̈̆̈̈̈ yere doğru bembeyaz elbiseli iki kişi bembeyaz bir sal (Tabut) omuzlamışlar götürüyorlar. Adam çok korkmuş ve hemen evine girmiş (KK: 5, 6, 8).

\section{DEĞERLENDIRME}

Günümüze kadar gelen tarihi eserlerden ve belgelerden anlaşıldığı üzere Uzuncaburç Helenistik dönemi, antik Yunan dönemini, ihtişamlı Roma medeniyetini ve Türk kültürünü yaşamış, yaşamakla da kalmamış bu dönemlerin hepsinden elde ettiği tarihi ve kültürel 
mirası günümüze kadar getirmeyi başarmış ender yerleşim yerlerinden birisidir. Bölgenin Türklerden önceki döneminde en önemli geçim kaynağı olan üzüm bağları ${ }^{2}$ ve şarap üretim kültürü Türklere zengin bir bağcılık birikimi bırakmıştır. Bu kültürel mirası devralan Türkler yok etmek yerine geliştirerek kendi kültürüne uyarlamayı tercih etmişlerdir. Çünkü üzüm de biraz Türkler gibidir. İnanç ve hayatta kalma arzusu ile yola çıkar. Kökleri her geçen gün biraz daha derine iner. Su bulamadıkça yılmaz, daha da derinlere iner. Her şey yolunda giderken bile bir anda düşman saldırısına uğrayabilir. Bu düşman bazen parazitler, bazen rüzgâr, bazen de rüzgârla taşınan tuz, kuraklık veya hastalıktır. Ancak "beni öldürmeyen şey daha da güçlendirir" diyen üzüm yoluna devam eder. Üzümler olgunlaşmaya başladığı zaman bağda bir iç hesaplaşma başlar. Bazı meyveler cılız görülür ve onlar kendilerini feda ederek diğerlerinin yolunu açarlar. Bunu bazen bağın kendisi yapar bazen de dış güç olan bahçıvan. Kalan üzümler ise yoluna devam eder ve en sonunda olgunlaşmış üzüm olarak nihayete ulaşır. Burada dönüş yolu, yeniden doğma süreci başlar. Bilgesinden aldığ1 feyzle üzüm ödülüne dönüşür (Bottoni, 2015, s. 13). Bu ödül antik çağlarda şaraptır; ancak şarap, İslam dinince yasaklandı̆̆ı için Türkler tarafından şarap üretilmemiş (Gürsoy, 2014, s. 114); onların kullandığı şarap üretim tekniklerinden de faydalanılarak pekmez üretilmiştir. Bu sebeple bugün Uzuncaburç'ta birçok üzüm çeşidi yetiştirilmekte ve bunlardan elde edilen pekmez, kuru üzüm gibi ürünler hem halkın kendisi tarafından tüketilmekte hem de satılarak gelir elde edilmektedir. Hem tadı hem kıvamı hem de besin değeri açısından çok kaliteli bir pekmez olan Uzuncaburç pekmezi, Silifke ve çevresinde tercih edilen bir pekmezdir. Çünkü bu pekmezler kaliteli Uzuncaburç üzümünden geleneksel yöntemlerle elde edilen organik bir besin kaynağıdır.

Aslında pekmez Türklerin bilmediği bir besin kaynağı değildir. Türk mutfak kültüründe pekmezle ilgili ilk kayıtlara Uygurlarda rastlamaktayız. Türkistan coğrafyasında yetiştirilen üzümlerden elde edilen pekmez (hem şarap hem pekmez için Bor kelimesini kullanıyorlar) üretim geleneğini (Altıntaş, 1999, s. 4; Uçar, 2019) Anadolu'ya getiren Türkler burada hazır buldukları ve daha sonra kendi yetiştirdikleri üzüm bağlarından pekmez üretmeye devam etmişlerdir. Hatta sadece üzümden değil dut, erik gibi meyvelerin de pekmezini yapmışlardır; ancak bunlar çalışmanın konusu değildir.

Türk mutfak kültürü ile ilgili Türkler tarafından yazılmış olan en eski eserlerden birisi olan olan "Ev Kadını" (İlk yayımlanması 1883) adlı eserde Adi Pekmez, Kükürtlü Pekmez ve Hardallı Pekmez (Ayşe Fahriye, 2018, s. 189) olmak üzere üç pekmez türünün tarifine yer verilmektedir. (Bu tariflere göre Uzuncaburç'ta üretilen pekmezler "Adi Pekmez" dediği türe girmektedir. İçine hiçbir şey karıştırılmadan yapılan saf pekmez anlamında kullanılan "adi" kelimesi basit veya kalitesiz anlamina gelmemektedir). Osmanlı döneminde pekmez, padişah sofrasına bile girmeyi başarmıştır. Fatih Sultan Mehmet zamanında saraya alınan besin maddeleri arasında 3 kıyye şinik pekmez de kayıtlara geçmiştir (Gürsoy, 2013, s. 95). Günümüz Türk mutfağında da pekmez önemli bir yer tutmaktadır. Yöresel mutfaklara bakıldığı zaman pekmez, şerbeti, pekmezli kış kabağı reçeli (Öztan, 2016, s. 353, 362), pekmezli hoşmak, pekmez şerbeti (Bayram, 2004, s. 365, 385), pekmezli palıza (Bayrak, 2015a, s. 364), pekmez helvası, pekmezli hoşaf (Bayrak, 2015b, s. 349, 380) gibi pek çok pekmez içerikli tatlılar sofraları süslemektedir. Ayrıca her yörenin kilerinde üzüm pekmezi mutlaka bulunmaktadır (Bayrak, 2015c, s.431; Bayrak, 2015a, s.420; Bayrak, 2015b, s. 437).

2 Tarihi kaynaklara göre bağcllık kültürü ile ilgili ilk bulgulara Akdeniz havzasının doğusunda Erken Tunç Çağı (M.Ö. 3. Binin ilk yarısı)'na tarihlenen yerleşim yerlerinde rastlanmaktadır (Söylemezoğlu, 2005, s. 2).

SEFAD, 2020; (43): 257-272 
Uzuncaburç'ta da pekmez özellikle soğuk kış günlerinde en çok tüketilen besinlerden birisidir. Pekmez karla karıştırılıp "karlı pekmez" şeklinde tüketilmekte, sabahları kahvaltı da tahinli pekmez yapılıp yenilmekte, bazen hafif sıcak su ile karıştııılıp şifa niyetine içilmekte, un ile karıştırılıp hafif kavrularak pekmez bulamacı yapıp özellikle çocuklara yedirilmektedir. Ayrıca pekmezin kan yaptığı, insanın içini sıcak tutup üşümeyi engellediği gibi inanışlar yörede çok yaygındır (KK: 1, 2,3).

Uzuncaburç'ta geleneksel yöntemlerle üretilen pekmezler yöre halkının ifadesi ile "şifa dağıtmaktadır" ve baldan bile kıymetlidir (KK: 2, 3, 5, 6, 7, 8, 9, 10). Çünkü Türklerin Orta Asya'dan getirdikleri pekmez geleneği ile Uzuncaburç'un Türkler öncesi dönemden kalma kaliteli üzüm bağlarının birleşmesi ile yeniden şekillenen pekmezcilik kültürü engin bir bilgi birikimine sahiptir. Yöre insanı pekmezin kıvamını, tadını, ne kadar süre pişmesi gerektiğini, nasıl soğutulması gerektiğini çoğu zaman ölçü aleti bile kullanmadan "göz kararı" denilen yöntemle bilecek kadar gelişmiş bir hassasiyete sahiptir. Bu hassasiyet asırların getirdiği bilgi ve tecrübe birikimi ile oluşmuştur. Günümüzde bu bilgi birikiminin gelecek kuşaklara aktarımı azalsa da devam etmektedir.

Pekmez pişirilen ocaklar, bakırdan yapılmış pekmez tavaları, delikli savuracaklar olan "kevgir"ler, bakır helke (bakraç)'ler, üzüm çiğnenen şıhranalık (havuz)'lar etnografyanın ve halk teknolojisinin nadide örneklerini oluşturmaktadır. Özellikle şıhranalık (üzüm çiğnenen havuz) ve ocak tamamen halkın kendi yaptığı eserlerdir. Ocak yapılırken eskiden tamamen taş ve kerpiç kullanılıyormuş. Bugün de ağırlıklı olarak taş ve kerpiç kullanılmakla birlikte taş ve betondan yapılan ocaklar da mevcuttur. Şıhranalıklar eski dönemden kalma (Görsel 7'deki gibi) taşa oyulmuş havuzlara benzetilerek taş ve kerpiç ile yapılmaya başlanmış bugün ise taş ve beton kullanılıyor. Kevgir ise tamamen yöre insanının tasarladığı bir savuracak olarak göze çarpmaktadır. Bakırdan yapılmış olan pekmez tavası ve helke (bakraç)'lar ise Silifke merkezde bulunan bakır ustalarından temin edilmektedir. Burada dikkat çekici husus, Uzuncaburçluların pekmez kaynatırken kendilerinden önce yaşamış olan yöre sakinlerden devraldıkları (aslında onların şarap üretmek için kullandığı) taşa oyulmuş şarap üretim yerlerini uzun bir süre kullanmaları daha sonra kendileri onlara benzer üretim yerleri kurmalarıdır. Bugün yörede kullanılan üzüm çiğneme havuzu, üzüm suyunun dinlendirilmesi için kullanılan havuzlar (günümüzde bu havuzların yerini kazanlar almıştır) geçmiş örneklerin benzerleridir.

Yöredeki pekmez üretimi sözlü kültür geleneğinin yaşatılması açısından da önemli bir yere sahiptir. Pekmez yapma işi uzun bir sürece yayılmaktadır. Çoğu zaman gece yarısına kadar süren pekmez kaynatma esnasında pekmez ocağının etrafına çocuklar, gençler ve yetişkinler toplanmaktadır. Bu esnada çaylar içilip közde pişmiş çörekler yenilirken özellikle yaşlılar tarafından gençlere fıkra, efsane, memorat gibi anlatı türlerinden örnekler anlatılmaktadır. Böylece bir sözlü kültür aktarım ortamı da oluşmaktadır. Yukarıda derleyebildiğimiz ve birkaç örneğine yer verdiğimiz anlatıların, yöre insanının günlük hayatından ve inanç dünyasından izler taşıdığı görülmektedir. Özellikle yörede hayalet inancının çok yaygın olduğu ve bu tür ortamlarda en çok anlatılan ve dinlenen anlatı türünün memoratlar olduğu tespit edilmiştir. 


\section{SONUÇ}

Yapılan araştırmadan da görüldüğü gibi Uzuncaburç'ta üzüm bağcllı̆ğ kökeni Helenistik döneme kadar giden eski ve köklü bir geçmişe sahiptir. Anadolu'yu yurt edinen Türkler, burada var olan bütün kültürel değerleri koruyup geliştirerek günümüze kadar getirmeyi ve ona kendi damgasını vurmayı başarmıştır. Uzuncaburç'ta da yöreye yerleşen Avşar Yörükleri Orta Asya'dan getirdikleri kültürel değerlerini yeni coğrafyanın imkân ve birikimleri ile harman edip geliştirmiştir. Pekmez üretimi de bu konulardan birisidir. Orta Asya Türk mutfağında bilinen ve tüketilen pekmez, Anadolu'ya geldikten sonra da Türk mutfak kültürünün bir parçası olmayı sürdürmüştür. Padişah sofrasından en fakir köy insanının sofrasına kadar her sofrada yerini alan pekmez, Uzuncaburç insanının da vazgeçilmez besinlerinden birisi olmuştur. Hatta pekmezin ne kadar değerli bir besin kaynağı olduğu fıkralara bile yansımıştır. Özellikle "Zengin Yiyeceği" adlı fıkrada pekmez krallara lâyık, sosyal statüsü yüksek bir yiyecek olarak görülmektedir. Bu bağlamda Uzuncaburç'ta geleneksel yöntemlerle pekmez üretimi geçmişten günümüze ulaşan kültürel bir miras olarak varlığını devam ettirmekte ve yöresel mutfak kültürü içindeki önemini korumaktadır. Diğer yandan pekmez üretimi esnasında etrafına toplanılan ocak, bir sözlü kültür üretim ve aktarım mekânı işlevi de görmektedir.

\section{SUMMARY}

Uzuncaburç named as Diocaiseria in the history and in Silifke district of Mersin province, is an old settlement established at the foothill of the Taurus Mountains. Today, Yörük Turkmens live in Uzuncaburç, in which the first settlement dates back to the Hellenistic period and which hosts many historical works belonging to the Ancient Greek and Roman periods. Molasses (pekmez) and foods with molasses have an important place in the culinary cultures of Turks who have succeeded in bringing out a civilization by blending the rich cultural heritage brought from Central Asia with the culture they found ready in Anatolia. The Turks who knew how to make molasses in the Uyghurs period in Central Asia lived and developed the grapery culture that was ready when they came to Anatolia and produced delicious molasses from the grapes they obtained from these vineyards. Since Uzuncaburç is a very favorable place for grapery, the previous inhabitants of the settlement grew a lot of grapes and consumed quality wines made from these grapes and exported them to other countries. Since the region was an important worship center of the period, it had a large population compared to its age, and it is understood that the trade was very lively. The main trade product is wine. After the Turks settled in the region, they preserved the vineyards and added grapes and products obtained from grapes to the livestock and dry farming as economic activity. However, there is a difference here. Turks preferred to make molasses instead of producing wine from grapes, especially with the influence of Islam. Today, the local people have a rich knowledge and cultural heritage about molasses making. In addition, since molasses is a difficult task that takes a long time, the jokes, legends, memoir-like narratives that the people tell each other have made molasses making a cultural activity where the oral cultural tradition is kept alive and transferred to the next generations. In this article, all this cultural heritage was compiled through field research and analyzed in terms of folklore.

SEFAD, 2020; (43): 257-272 


\section{KAYNAKÇA}

Altıntaş, Ö. (1999). Çal yöresinden üretilen üzüm çeşitleri ve yörede üretilen pekmezlerin bazı özellikleri (Yayınlanmamış yüksek lisans tezi). Pamukkale Üniversitesi, Denizli.

Aslan, İ. (1988). Silifke tarihi. Adana: Kemal Matbaası.

Ayşe F. (2018). Ev kadını. (Haz. Turgut Kut). İstanbul: Çiya Yayınları.

Başal, Ş. (1993). Antik Silifke ve çevresi. Mersin: Gözde Ofset.

Bayrak, M. F. (2015a). Güneydoğu Anadolu yemekleri. İstanbul: Alfa Yayınları.

Bayrak, M. F. (2015b). İç Anadolu yemekleri. İstanbul: Alfa Yayınları.

Bayrak, M. F. (2015c). Doğu Anadolu yemekleri. İstanbul: Alfa Yayınları.

Bayram, M. (2004). Geleneksel tadıyla lezzet soframız. İstanbul: Çelik Yayınevi.

Bottoni, E. U. (2015). Üzümler ve insanlar toprak ana, bağban baba. İstanbul: Yapı Kredi Yayınları.

Gürsoy, D. (2013). Yiyelim içelim, tarihini bilelim. İstanbul: Oğlak Yayıncılık.

Gürsoy, D. (2014). Deniz Gürsoy'un gastronomi tarihi. İstanbul: Oğlak Yayıncılık.

Öztan, T. T. (2016). Bir lezzet cenneti gurme kent Gaziantep mutfağı. İstanbul: Oğlak Yayıncılık.

Söylemezoğlu, G. (2005). Arkeolojik buluntuların ışığı altında Anadolu bağcllığının tarihçesi, K. Toygar ve N. B. Toygar (Haz.). Ankara'da bağgcllk ve bağ kültürü içinde Ankara: Birlik Matbaacilik.

Şükürov, Q. (2007). Geçmişten günümüze Avşarlar, Hayati Beşirli, İbrahim Erdal (Ed.). Anadolu'da Yörükler tarihi ve sosyolojik incelemeler içinde Ankara: Phoenix Yayınları.

Taşkıran, C. (2009). Silifke Ulu Kent. Silifke: Sim Matbaacılık.

Uçar, A. (2019, 7 Şubat). Geleneksel Türk tadı pekmez. Erişim adresi: http://sozriko.blogspot.com/2019/02/geleneksel-turk-tad-pekmez.html

\section{KAYNAK KİŞİLER}

KK 1: Fatmana Yılmaz, Okuma yazması yok, 71 yaşında

KK 2: Elife Kabak, Lise mezunu, 54 yaşında

KK 3: Gürgel Sak, Okuma yazması yok, 75 yaşında

KK 4: Emine Güçlü, Okuma yazması yok, 74 yaşında

KK 5: Mustafa Kabak, Okuma yazması yok, 81 yaşında

KK 6: Süleyman Kabak, İlkokul mezunu, 55 yaşında

KK 7: Davut Üre, İlkokul mezunu, 65 yaşında

KK 8: Muhammet Üre, İlkokul mezunu, 70 yaşında

KK 9: Mahmut Güçlü, Okuma yazması yok, 76 yaşında

KK 10: Veli Yılmaz, 80 yaşında, İlkokul mezunu 
EKLER:

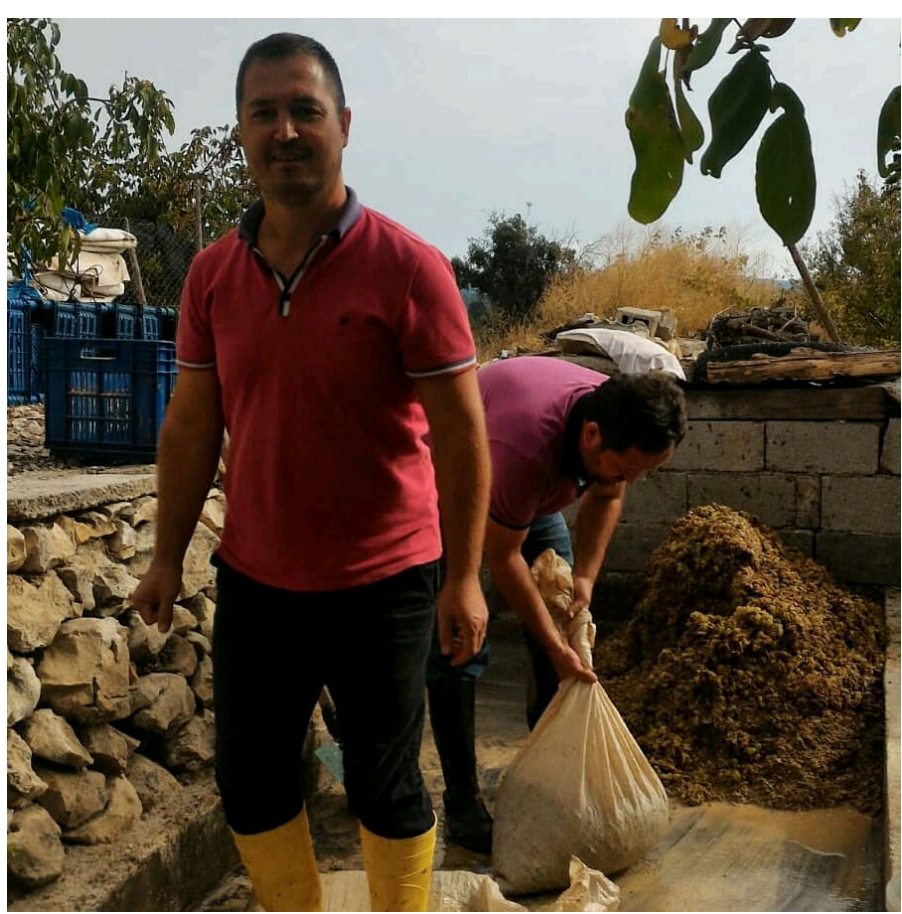

Görsel 1: Şıhranalıkta Üzüm Çiğneme İşlemi

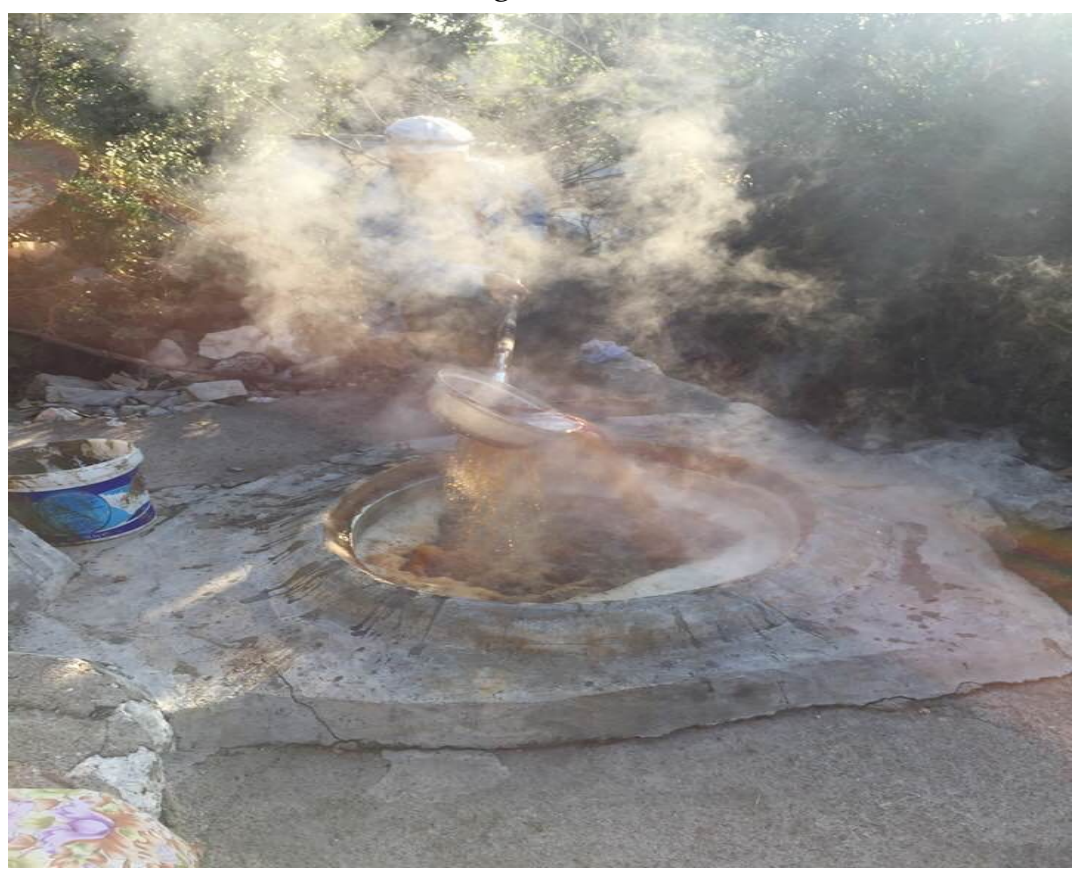

Görsel 2: Pişen Pekmez 


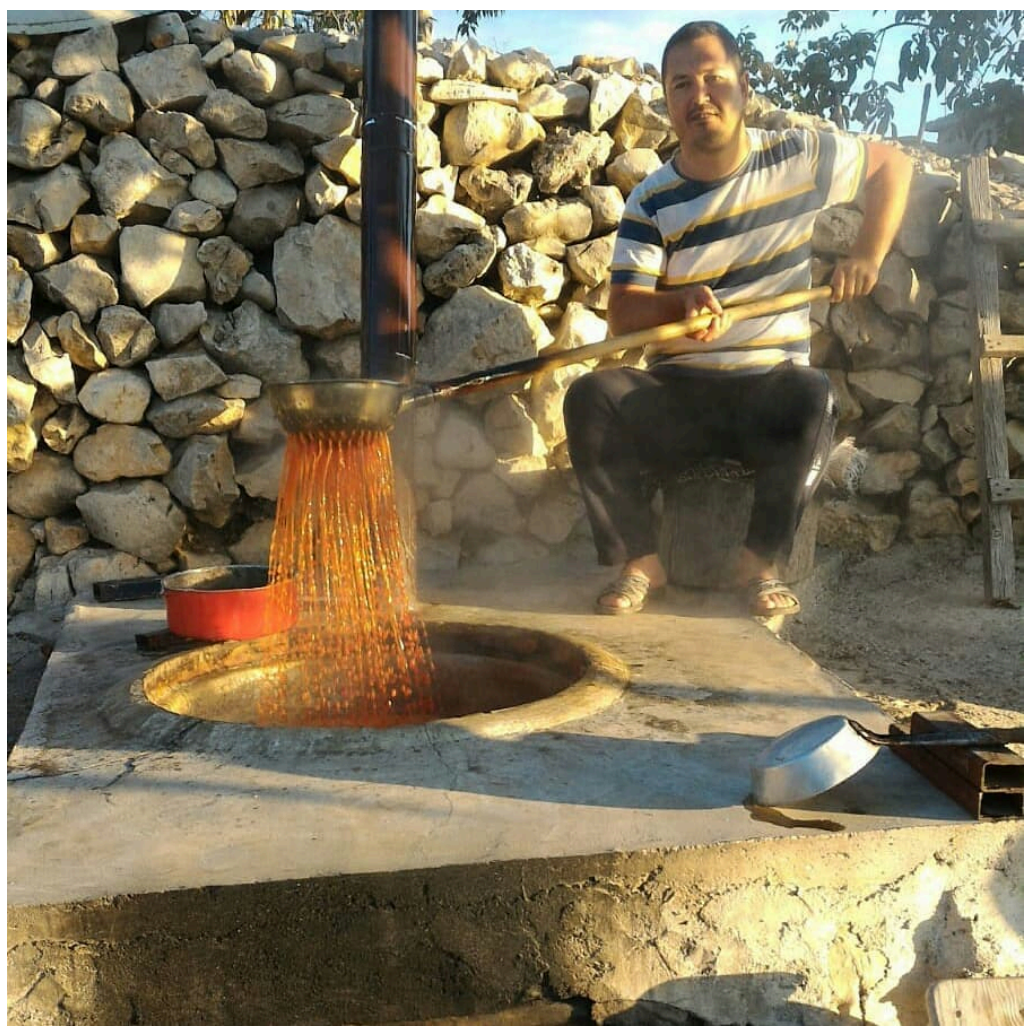

Görsel 3: Kevgir ile Pekmez Savurma

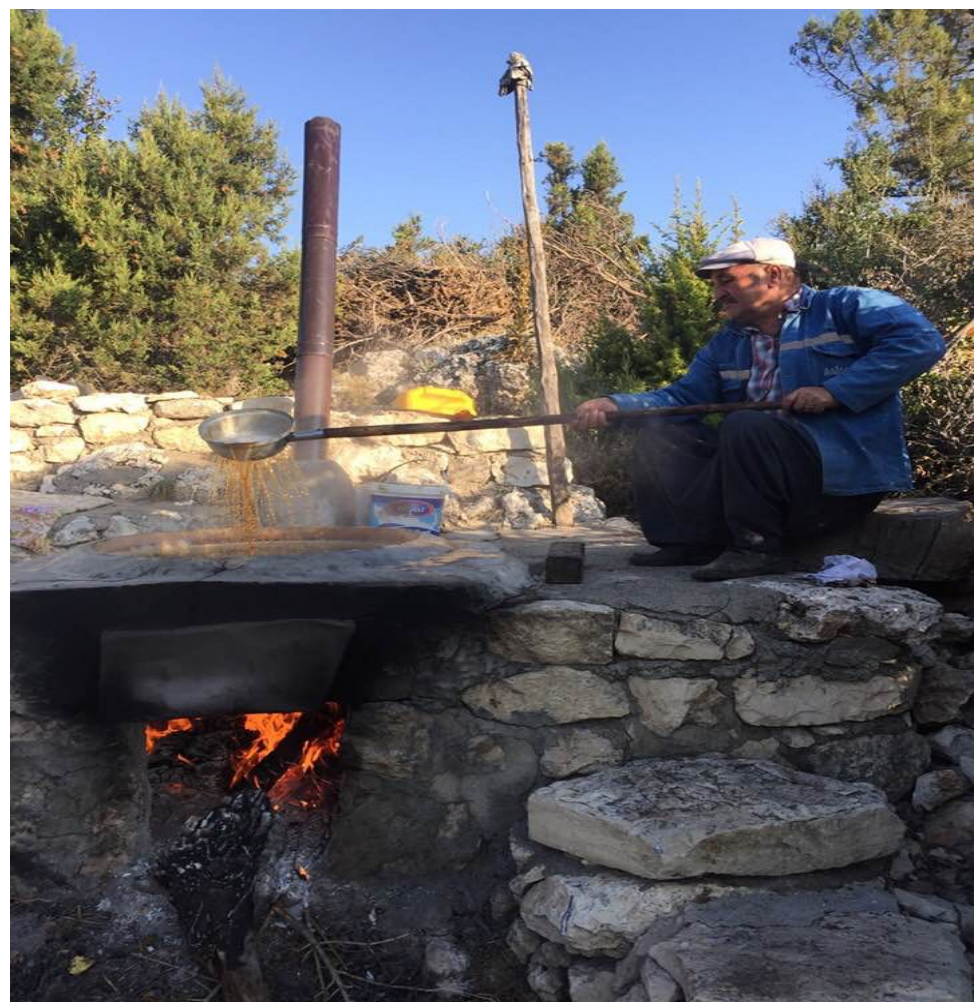

Görsel 4: Pekmez Ocağı ve Pişirme İşlemi 


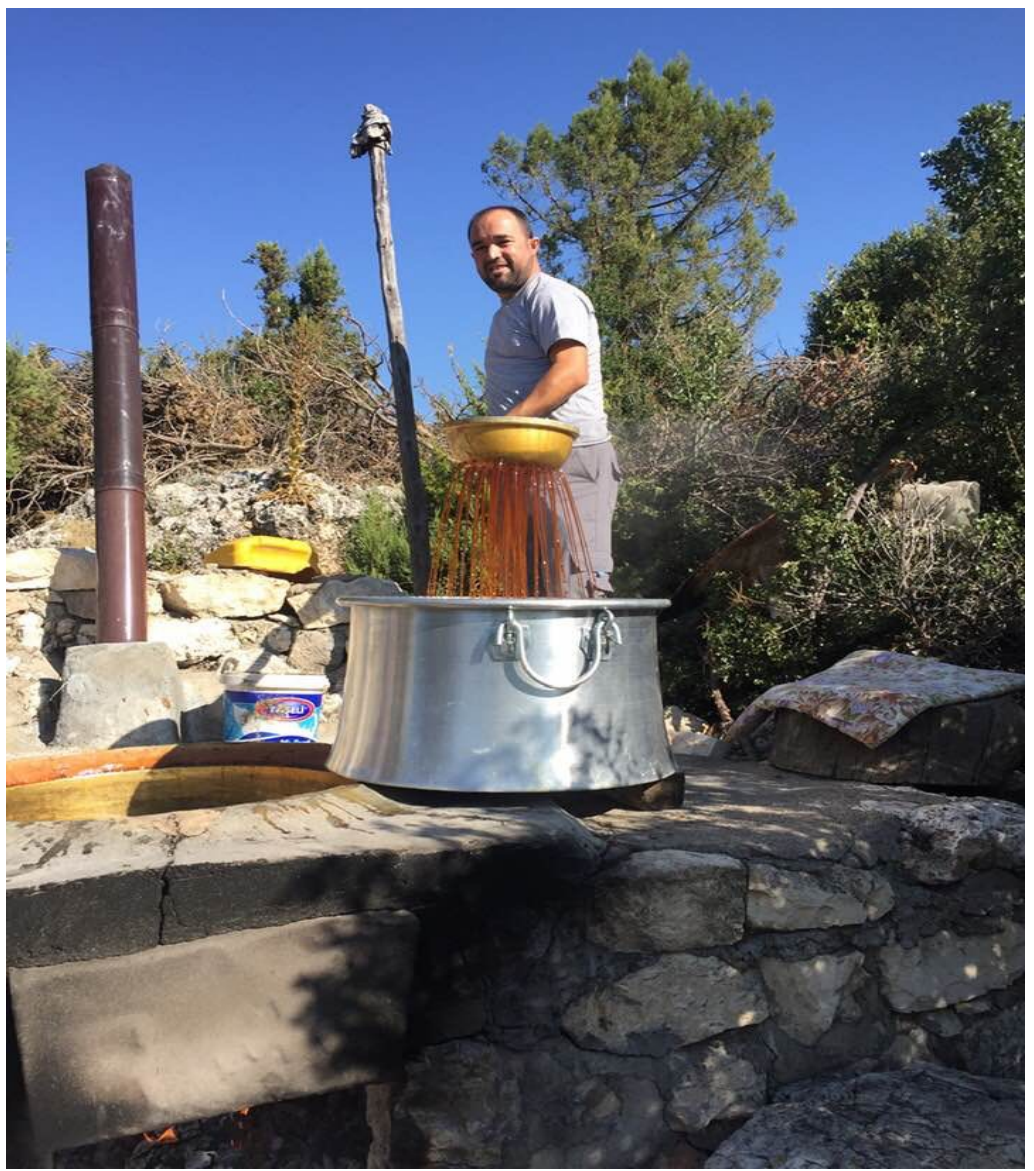

Görsel 5: Pekmez Soğutma İşlemi

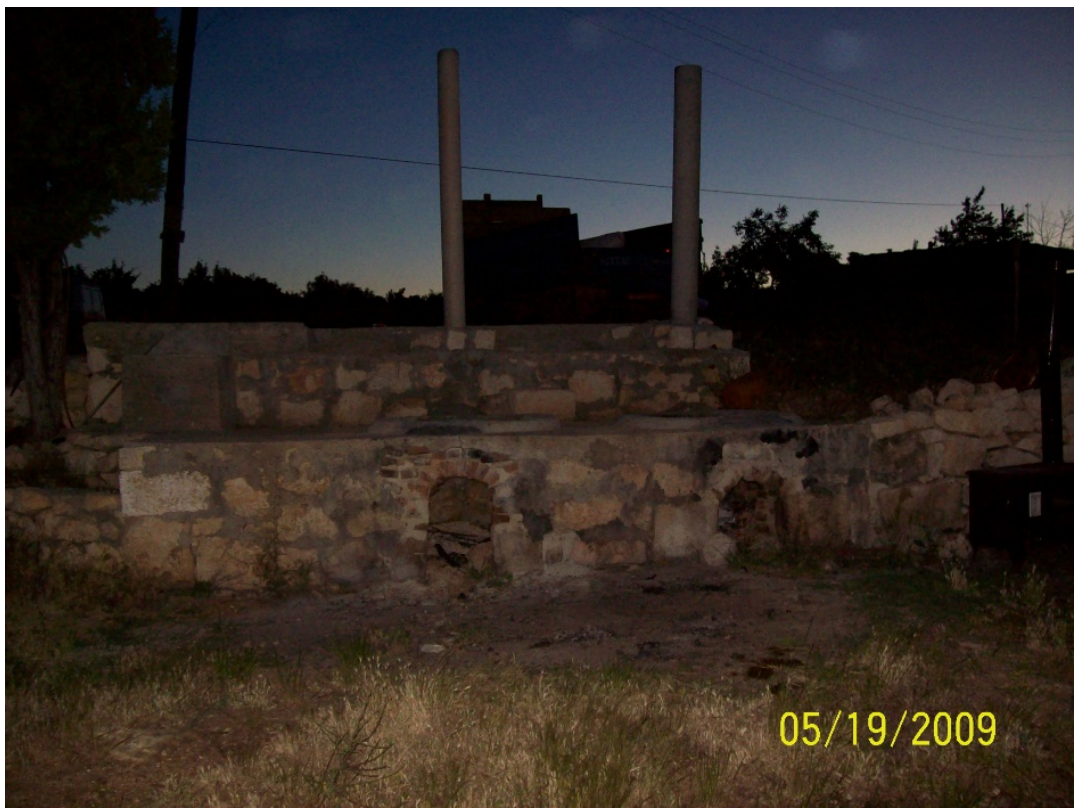

Görsel 6: İkili Pekmez Ocağ1 


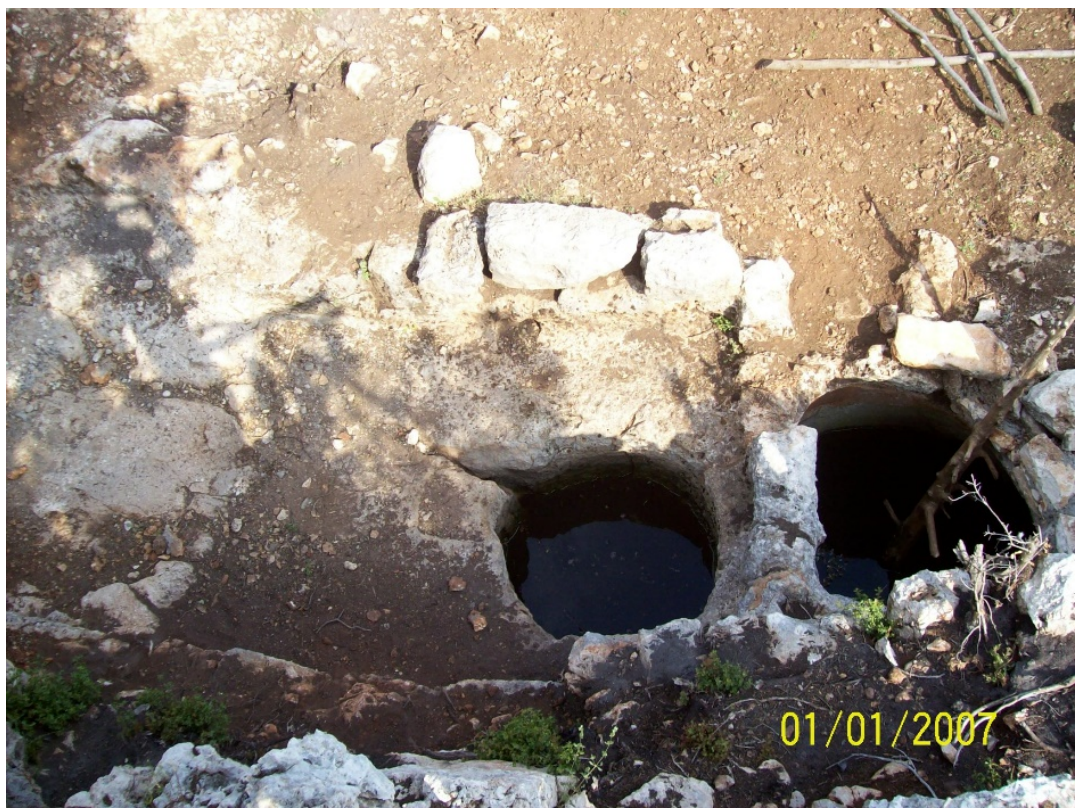

Görsel 7: Antik Dönemden Kalma Şarap Üretim Yeri (Şarap Yalağı)

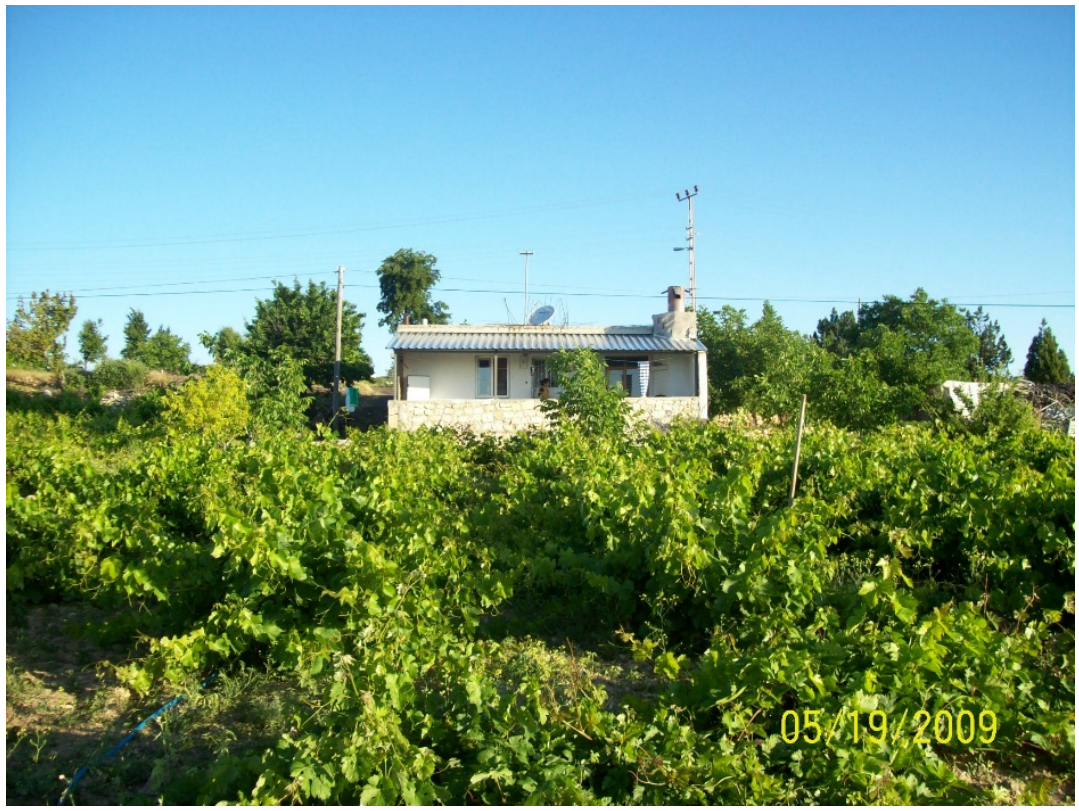

Görsel 8: Uzuncaburç'ta Üzüm Bağları. 